\title{
PERSPECTIVE \\ Practicing Medicine with Colleagues: Pitfalls from Social Psychology Science
}

\author{
Donald A. Redelmeier, MD, FRCPC, MS(HSR), FACP $1,2,3,4,5$ and Lee D. Ross, PhD ${ }^{6,7}$ \\ 'Department of Medicine, University of Toronto, Toronto, Canada; ${ }^{2}$ Evaluative Clinical Sciences, Sunnybrook Research Institute, Toronto, Canada; \\ ${ }^{3}$ Institute for Clinical Evaluative Sciences in Ontario, Toronto, Canada; ${ }^{4}$ Centre for Leading Injury Prevention Practice Education \& Research, \\ Toronto, Canada; ${ }^{5}$ Sunnybrook Health Sciences Centre, G-151, Toronto, Ontario, Canada; ${ }^{6}$ Department of Psychology, Stanford University, \\ Stanford, USA; ' 5 Stanford Center on International Conflict and Negotiation, Stanford, USA.
}

This perspective reviews three pitfalls from psychology science that can distort clinical assessments and contribute to interpersonal conflicts. One pitfall is the illusion that one's own subjective perceptions or judgments are objective observations or interpretations that reasonable colleagues would share. A second pitfall involves selfserving situational attributions rather than disposition attributions for explaining missteps after things go wrong. A third pitfall is confirmation bias that leads to a perseverance of erroneous beliefs, a tendency to mostly seek supportive colleagues, and a failure to check for dissenting viewpoints. An awareness of these three pitfalls may help clinicians improve patient care when practicing with colleagues.

KEY WORDS: medical error; fallible reasoning; judgment and decisions; illusion of objectivity; situational factors; confirmation bias.

J Gen Intern Med 34(4):624-6

DOI: $10.1007 / \mathrm{s} 11606-019-04839-5$

(C) Society of General Internal Medicine 2019

\section{INTRODUCTION}

It is easy to recognize cognitive and motivational biases that produce conflict in political discourse. While not a subject of regular news-media coverage, the same interpersonal conflicts may compromise clinicians providing daily medical care. Effective practice demands that clinicians have some insight into human motivations and behavior. ${ }^{1}$ Good clinicians may also know a great deal about the nature of their own colleagues and professional networks. However, some pitfalls around interpersonal interactions are subtle and easily go unrecognized. These pitfalls have been uncovered by provocative research in psychology, particularly social psychology science. $^{2}$

Social psychology science examines how people perceive, think about, and act toward other people. ${ }^{3}$ Insights from social psychology can be vital for collaborating with medical colleagues; moreover, the insights can also help illuminate common pitfalls. A failure to appreciate such insights may not

Received July 4, 2018

Revised October 25, 2018

Accepted January 9, 2019

Published online January 31, 2019 matter when interpreting a kidney biopsy, for example, but a lack of such insights can frustrate efforts in organizing people to perform the kidney biopsy in the first place. More generally, successfully initiating a diagnostic test, surgical procedure, referral consultation, or follow-up visit requires knowledge about the way people make judgments and decisions when they interact with each other.

A comprehensive list of social psychology science might include studies on motivation, incentives, self-control, forgetfulness, conflicts, idiosyncratic personalities, diffusion of responsibility, and thoughtless habits. ${ }^{4}$ Herein, we do not attempt to review that vast literature on diverse sources of interpersonal conflict; instead, we discuss three specific pitfalls that can comprise effective interpersonal interactions (Table 1). Each has counterintuitive features, is relevant to patient care, has been validated in highly replicated research, and appears in standard psychology textbooks. However, these pitfalls are rarely discussed in medical training or MEDLINE searches.

\section{The Objectivity Illusion}

Medical practice, like all professions, requires judgments based on perceptions. Clinicians need to trust their senses, show confidence, and act decisively. They do so, however, with a conviction of personally seeing the world objectively and believing that people who disagree must be less informed, rational, or objective. This illusion of objectivity means, for example, that a difference in opinions between a clinician and a hospital administrator is usually ascribed to a deviant bias such as self-interest, external pressures, or desire for institutional approval. While some of these factors may partially contribute to disagreements, the individuals may fail to explore the real sources of information in a more open-minded dialogue.

A consequence of the objectivity illusion is a tendency to overestimate the extent to which personal views are widely shared. One classic study, for example, asked university students $(n=80)$ to estimate whether nuclear weapons would be used in warfare in the next twenty years and to estimate the consensus of their peers. 5 Those who said "yes" tended to think their peers would similarly say "yes" whereas those who said "no" thought only a minority of their peers would instead 
Table 1 Avoiding Pitfalls in Collegial Interactions

\begin{tabular}{|c|c|c|c|c|}
\hline$\overline{\text { Pitfall }}$ & Definition & Example & Strategy & Example \\
\hline Objectivity illusion & $\begin{array}{l}\text { Presume personal } \\
\text { objectivity }\end{array}$ & $\begin{array}{l}\text { "Colleagues who start new drugs } \\
\text { before me are unwise and after me } \\
\text { are too slow" }\end{array}$ & $\begin{array}{l}\text { Encourage a } \\
\text { diversity of feedback }\end{array}$ & $\begin{array}{l}\text { "Reasonable people can } \\
\text { disagree on the best choice and } \\
\text { I may be off" }\end{array}$ \\
\hline $\begin{array}{l}\text { Self-serving } \\
\text { situational } \\
\text { attributions }\end{array}$ & $\begin{array}{l}\text { Misunderstanding } \\
\text { situational influences }\end{array}$ & $\begin{array}{l}\text { "My mistakes reflect circumstances } \\
\text { whereas your mistakes indicate a } \\
\text { character flaw" }\end{array}$ & $\begin{array}{l}\text { Diligently check the } \\
\text { context of a behavior }\end{array}$ & $\begin{array}{l}\text { "I might have made the same } \\
\text { mistake but for the grace of } \\
\text { God go I" }\end{array}$ \\
\hline Confirmation bias & $\begin{array}{l}\text { Avoid dissenting } \\
\text { viewpoints }\end{array}$ & $\begin{array}{l}\text { "My hunch feels correct and I will } \\
\text { next strengthen my arguments } \\
\text { further" }\end{array}$ & $\begin{array}{l}\text { Invite someone to } \\
\text { play devil's advocate }\end{array}$ & $\begin{array}{l}\text { "Since I may be wrong, what's } \\
\text { an alternative I should also } \\
\text { consider" }\end{array}$ \\
\hline
\end{tabular}

say "yes" (59\% vs 31\%, $p=0.002)$. The same illusion can similarly cause alcoholic patients to judge their alcohol drinking as normal. ${ }^{6}$ This illusion could also lead clinicians to persist in outdated practices and fail to recognize when they are out-of-step with their peers.

The objectivity illusion promotes a sense that the clinician is tone-deaf. Just as a motorist considers those who are driving faster or slower as either a maniac or a doofus, the clinician is apt to label a colleague who recommends more intensified care as too aggressive and to label a colleague who recommends more patience as too timid. That is, a failure to recognize that one's own perceptions are biased can lead to unwarranted disparaging inferences about another colleague's competence, diligence, values, or sense of humor. The objectivity illusion notoriously leads a clinician to believe he or she is the only one who has elicited the correct history or made the right diagnosis, and thus is obliged to correct all others who disagree.

Maintaining some humility, actively exchanging the basis for one's reasons, and expressing a genuine willingness to change one's mind might foster more collegial medical practice. $^{7}$

\section{Self-Serving Situational Attributions}

Honest mistakes between thoughtful clinicians will inevitably arise in collegial patient care. However, people are inclined to attribute their own actions to situational demands but attribute the actions of others to personal dispositions. ${ }^{8}$ An important example of this self-serving bias is the tendency for people to attribute their own lapses to the surrounding circumstances and other people's lapses to ingrained personal faults, intentions, and limitations. For example, an individual clinician can explain away his or her own failure to elicit a detailed history to external pressures ("I was busy that day") while viewing the same mistake in another colleague as reflective of a character flaw ("he was lazy and uncaring").

Psychology science has offered many demonstrations of such biased attribution. One famous study asked college students $(n=324)$ at Dartmouth and Princeton to view a film of a football game between their own colleges and count the number of flagrant player infractions. ${ }^{9}$ The results suggested the two groups saw a different game, with differing perceptions about who initiated an infraction and who merely responded in self-defense. Further analyses also showed large differences in judgments about whether an infraction was intentional or accidental. Seeing what one wants to see can produce similarly biased assessments in medicine, such as when patients incorrectly think a newly renovated clinic is offering better treatment despite no objective change in the quality of care. ${ }^{10}$

Disappointing care can reflect situational pressures rather than a deficient colleague. That is, a different colleague would have done no better in the same situation. Similarly, excellent care may reflect a particularly advantageous situation rather than better training, superior skill, or exceptional concern. In both cases, more careful observation and thoughtful attention to situational factors is required for an accurate assessment of how much to trust another colleague. ${ }^{11}$ The required detective work is made more difficult because the colleagues, themselves, may be unaware of the relevant situational factors, may underestimate or overestimate such factors, or may feel too awkward to discuss such influences openly. ${ }^{12}$

Clinicians need to guard against the tendency to make unwarranted negative attributions about a colleague's trustworthiness based on an observation of a single instance of a medical mistake. ${ }^{13}$

\section{Confirmation Bias}

Collegial patient care also involves times of confusion marked by uncertainties rather than mistakes. In such cases, individuals are apt to seek supportive colleagues for reassurance. Psychologists refer to this tendency as "confirmation bias" which involves searching for, interpreting, recalling, or accepting information that confirms rather than challenges an existing belief. A blatant example would be a vitamin D enthusiast who hunts for anecdotes to reinforce an idea of vitamin $\mathrm{D}$ deficiency rather than conducting a dispassionate summary of evidence. A more familiar example is a patient with chest pain who is worked-up by cardiology to rule-out heart disease with no deliberate evaluation to directly diagnose alternative possibilities such as an aortic aneurism.

One demonstration of confirmation bias in psychology research involves selective Internet search activity. In this study, participants $(n=156)$ first completed a pretest survey of contentious personal beliefs such as whether they self-identified as pro-life or pro-choice. ${ }^{14}$ Subsequently, the participants received 
a free subscription to an online magazine with software tracking the time spent reading pro-life or pro-choice articles. As expected, those who had a baseline belief favoring pro-life spent one-third more minutes per day reading articles that were prolife than those who had a baseline belief favoring pro-choice ( 2.5 vs $1.9, p=0.002$ ). This pattern shows the general tendency of seeking information that matches preconceptions, similar to patients with selective recall bias who mistakenly believe stormy weather can cause worsening arthritis pain. ${ }^{15}$

A way to lessen confirmation bias in medical care, therefore, is to deliberately ask a colleague to argue the opposite view. ${ }^{16}$ This will take time and requires substantial self-discipline by both clinicians. A compromise strategy might be to allow confirmation bias to run rampant when initially assessing the patient, to practice meticulous follow-up thereafter, and to initiate a search for contrary views if the course does not go as anticipated. ${ }^{17} \mathrm{~A}$ further safeguard is to declare explicitly the anticipated course so subsequent follow-up is not slanted by a faulty memory. ${ }^{18}$ Admittedly, these strategies demand willpower since clinicians prefer agreeable collegial conversation and many medical decisions will be right by chance alone.

Gentle reminders might strengthen clinical care through regular warnings on how confirmation bias is the opposite of the standard scientific approach that requires searching for disconfirming evidence. ${ }^{19}$

\section{CONCLUSION}

Medical care regularly includes cases where a colleague says something the responsible clinician does not want to hear. Findings from psychology science can help explain the ways in which such interpersonal conflict leads to frustration, distrust, and attributions of incompetence. Of course, there is disagreement about how much an awareness of pitfalls can mitigate the conflict. ${ }^{20}$ This now provides a direction for future research on how to reduce interpersonal conflict in collegial patient care and work with colleagues who hold contrary views. At present, we can only speculate about the clinical advantages of showing greater humility, willingness to consider thoughtfully the views of colleagues, and sincere openness to change perspectives.

Acknowledgements: We thank the following for helpful comments: Arnie Aberman, Allan Detsky, Andrew Lustig, Barry McLellan, Raffi Rush, Fizza Manzoor, Camille Schull, Gillian Spiegle, and Christopher Yarnell.

Corresponding Author: Donald A. Redelmeier, MD, FRCPC, MS(HSR), FACP; Sunnybrook Health Sciences Centre, G-151, Toronto, Ontario, Canada (e-mail: dar@ices.on.ca).
Funding Information This project was supported by the Canada Research Chair in Medical Decision Sciences, the BrightFocus Foundation, and the Canadian Institutes of Health Research.

\section{Compliance with Ethical Standards:}

Conflict of Interest: The authors declare that they do not have a conflict of interest.

Publisher's Note: Springer Nature remains neutral with regard to jurisdictional claims in published maps and institutional affiliations.

\section{REFERENCES}

1. Windish DM. Reflective practice and stress: helpful, harmful or uninfluential in critical thinking. J Gen Intern Med 2015;30(9):1237-8.

2. Gilovich T, Ross L. The wisest in the room. New York: Simon \& Schuster, 2015.

3. Gilovich T, Keltner D, Chen S, Nisbett RE. Social psychology $\left[4^{\text {th }}\right.$ edition]. New York: W. W. Norton \& Co, 2016.

4. Redelmeier DA, Cialdini RB. Problems for clinical judgement: 5 . Principles of influence in medical practice. CMAJ 2002;166(13):1680-4.

5. Ross L, Greene D, House $\mathbf{P}$. The false consensus effect: An egocentric bias in social perception and attribution processes. J Exp Soc Psychol 1977;13(3):279-301.

6. Leavy RL, Dunlosky JT. Undergraduate student and faculty perceptions of problem drinking. J Stud Alcohol 1989;50(2):101-7.

7. Monteiro SD, Sherbino J, Patel A, Mazzetti I, Norman GR, Howey E. Reflecting on diagnostic errors: taking a second look is not enough. J Gen Intern Med 2015;30(9): 1270-4.

8. Jones EE, Nisbett RE. The actor and the observer: Divergent perceptions of the causes of behavior. Morristown, NJ: General Learning Press, 1971.

9. Hastorf $\mathbf{A H}$, Cantril $\mathbf{H}$. They saw a game; a case study. J Abnorm Soc Psychol 1954;49(1):129-134.

10. Becker F, Sweeney B, Parsons K. Ambulatory facility design and patients' perceptions of healthcare quality. HERD 2008;1(4):35-54.

11. Leykum LK, Chesser H, Lanham HJ, Carla P, Palmer R, Ratcliffe T, Reisinger H, Agar M, Pugh J. The association between sensemaking during physician team rounds and hospitalized patients' outcomes. J Gen Intern Med 2015;30(12):1821-7.

12. Ross L, Nisbett RE. The person and the situation: perspectives of social psychology. London: McGraw-Hill, 2011.

13. Blumenthal-Barby JS, Krieger H. Cognitive biases and heuristics in medical decision making: a critical review using a systematic search strategy. Med Decis Mak 2015;35(4):539-57.

14. Knobloch-Westerwick S, Meng J. Looking the other way: Selective exposure to attitude-consistent and counterattitudinal political information. Commun Res 2009;36(3):426-448.

15. Redelmeier DA, Tversky A. On the belief that arthritis pain is related to the weather. Proc Natl Acad Sci U S A 1996;93(7):2895-6.

16. Redelmeier DA. Improving patient care. The cognitive psychology of missed diagnoses. Ann Intern Med 2005;142(2):115-20.

17. Redelmeier DA, Ferris LE, Tu JV, Hux JE, Schull MJ. Problems for clinical judgement: introducing cognitive psychology as one more basic science. CMAJ 2001;164(3):358-60.

18. Redelmeier DA, Dickinson VM. Judging whether a patient is actually improving: more pitfalls from the science of human perception. J Gen Intern Med 2012;27(9):1195-9.

19. Saposnik G, Redelmeier D, Ruff CC, Tobler PN. Cognitive biases associated with medical decisions: a systematic review.BMC Med Inform Decis Mak 2016;16(1): 138.

20. Croskerry $\mathbf{P}$, Singhal G, Mamede $\mathbf{S}$. Cognitive debiasing 2: impediments to and strategies for change. BMJ Qual Saf 2013;22 Suppl 2:ii65-ii72. 